УДК: 338.45:553.98(571.56-15)

DOI $10.21661 / \mathrm{r}-118275$

\title{
А.А. Пахомов
}

\section{ЗАПАДНО-ЯКУТСКИЙ НЕФТЕГАЗОВЫЙ КЛАСТЕР: АНАЛИЗ, ОЦЕНКА И ПЕРСПЕКТИВЫ РАЗВИТИЯ}

Аннотация: в статье дана оченка основных структурных сдвигов в экономике региона как условий развития Западно-Якутского нефтегазового кластера; отражены возможности создания территории опережающего развития в Западной Якутии; осуществлена оценка природно-ресурсного, экономического, инвестиционного потенциала; дана оценка развития энергетики и транспортной инфраструктуры; дана оценка расселения населения, потенщиала и специализации населенных пунктов; дана характеристика демографических процессов, воспроизводства населения, миграционных потоков.

Ключевые слова: Западно-Якутский регион, нефтегазовый кластер, природно-ресурсный потенциал, инвестиционный потенциал, энергетическая $и$ транспортная инфраструктура, специализация населенных пунктов, демографические прочессы.

\section{A.A. Pakhomov}

\section{WESTERN-YAKUTIAN OIL AND GAS CLUSTER: ANALYSIS, ASSESSMENT AND PROSPECTS OF DEVELOPMENT}

Abstract: this article gives an assessment of main structural changes in an economy of region as conditions of development of Western-Yakutian oil and gas cluster, reflects the possibilities of territories creation of priority development in Western Yakutia, estimates the natural resource, economic, investment potential and the development of energy engineering and transport infrastructure, it also tries to estimate the population distribution, potential and specialization of settlements, characterizes the demographic processes, population reproduction, and migration flows. 
Keywords: Western-Yakutian region, oil and gas cluster, natural resource potential, investment potential, energy and transport infrastructure, specialization of settlements, demographic processes.

Сбалансированное пространственно-экономическое развитие экономики Республики Саха (Якутия) подразумевает развитие актуальных к освоению Центральной и Южной Якутии, а также и Западно-Якутского региона. Его перспективное развитие позволит осуществить выход на мировые и межрегиональные рынки с конкурентоспособной экспортной минерально-сырьевой продукцией, позволяющей использовать полученные доходы на создание и развитие производств с высокой добавленной стоимостью, а также уникальной самобытной продукцией и услугами Республики Саха (Якутия).

Западно-Якутский регион включает алмазодобывающий кластер и формирующийся Западно-Якутский нефтегазовый кластер, которые расположены в районах, составляющих экономическую зону федеральной дороги «Вилюй», имеющей значительный транзитный потенциал в создании единого социальноэкономического пространства республики. В связи с этим, комплексный анализ возможностей и рисков социально-экономического развития Западно-Якутского нефтегазового кластера имеет несомненную научную актуальность и практическую значимость для устойчивого пространственно-экономического развития Якутии.

В статье рассмотрим оценку современного пространственно-экономического развития Западно-Якутского нефтегазового кластера на основе природноресурсного, экономического и инвестиционного потенциала региона, энергетической и транспортной инфраструктуры, потенциала и специализации населенных пунктов, их доступности и изолированности, а также демографических процессов, воспроизводства населения и миграционных потоков.

Западная Якутия обладает значительными запасами нефтеводородного сырья. К наиболее крупным из месторождений относятся Среднеботуобинское, Та- 
лаканское и Северо-Талаканское месторождения. Прогнозные геологические ресурсы оцениваются в 12 трлн м3 газа и 2,6 млрд тонн нефти. Достигнутая степень освоенности прогнозных ресурсов в республике составляет в среднем $20 \%$.

Перспективы развития газовой промышленности в Западной Якутии связаны с освоением Чаяндинского месторождения, которое позволит с 2019 г. резко нарастить объемы добычи газа в республике для экспорта в страны Азиатско-Тихоокеанского региона, а в Западной Якутии будет реализован третий мегапроект по масштабной добыче природного газа, который сделает экономику региона многоотраслевой.

Существующий опыт формирования и развития нефтегазовой промышленности северных территорий наглядно показывает, что в условиях широкомасштабного освоения углеводородных ресурсов необходимо усиление мер преимущественного развития производств и комплексов регионального назначения, способных существовать и эффективно поддерживать самодостаточную экономику самого субъекта (республики), даже и после ухода крупных корпораций и закрытия производств международного назначения. В этом плане, для того чтобы контролировать и рационально управлять положением региональной нефтегазовой отраслью в перспективе потребуется:

- разработка региональной политики в области делового партнерства с крупными холдинговыми компаниями;

- выбор и реализация приоритетных направлений развития отраслей НГК через систему распределения и доступа к углеводородным ресурсам;

- усиление участия региона не только в развитии энергетического комплекса, решении проблем экологической сохранности территорий, но и в устойчивом развитии его экономики.

Перспективы конкурентного развития нефтегазовой промышленности Западной Якутии возможны при их кластерном развитии, при этом будет сформирован Западно-Якутский нефтегазовый кластер мирового уровня, который по стоимости извлекаемого сырья превзойдёт стоимость всех других минеральносырьевых ресурсов в республике. 
Рост экономического потенциала за счет создания нефтегазового кластера Западной Якутии является основополагающим фактором конкурентоспособности и социально-экономического развития региона и может способствовать развитию других затратных перерабатывающих производств, а также традиционных отраслей хозяйствования на Севере, которые требуют больших дотационных вложений.

В настоящее время Западная Якутия обеспечивает 70\% объема производства добывающей промышленности, 17\% строительства, 15\% сельского хозяйства, около 6\% обрабатывающей промышленности республики. Объем товаров, работ и услуг по разделу В «Рыболовство, рыбоводство» незначителен. С учетом малого бизнеса на долю Западной Якутии приходится почти половина $(48,5 \%)$ объема производства основных видов экономической деятельности (по разделам $\mathrm{A}, \mathrm{B}, \mathrm{C}, \mathrm{D}, \mathrm{F})$ республики.

Инвестиционный потенциал Западной Якутии в перспективе обеспечен реализацией крупнейших инвестиционных проектов в России - ВСТО и «Сила Сибири». В условиях кризиса в алмазодобыче эти проекты во многом будут предопределять будущее развитие региона, безусловно усиливая его промышленную специализацию, обеспечивая дальнейший устойчивый рост ВРП РС (Я), а также налоговых поступлений в консолидированный бюджет республики. В 2013 г. налоговые поступления от алмазодобычи составили 15,6 млрд руб. против 11,2 млрд руб. от нефтегазовых компаний в 2013 г. и 22,1 млрд руб. в 2014 г.

Завершение инвестиционного этапа проектов в сфере нефтегазовой промышленности в 2007-2009 гг. и в настоящее время во многом предопределяют ожидаемый в среднесрочной перспективе инвестиционный спад в Западной Якутии. На этом горизонте временного планирования новые крупные проекты реализовываться не будут, поэтому на первый план выйдут проекты развития традиционных отраслей - сельского хозяйства, обрабатывающей промышленности, что станет стимулом для строительства. 
Энергетическая инфраструктура Западного энергорайона представлена нефтяной, газовой, угольной промышленностью и электроэнергетической отраслью. В регионе практически полностью сосредоточены все мощности по добыче нефти и газа в Республике Саха (Якутия).

Перспективы развития нефтяной промышленности связаны с добычей и транспортировкой нефти в основном из Талаканского, Среднеботуобинского НГКМ и Алинского ГНМ, в том числе создания производства нефтепереработки в Мирнинском и Ленском районах республики для обеспечения местной продукцией нефтепереработки и удешевления завозимого топлива для дизельных электростанций и автотранспорта.

Газовая промышленность связывает долгосрочное устойчивое газоснабжение Западного энергорайона республики с Среднеботуобинского НГКМ, Средневилюйского, Отраднинского и Стреднетюнгского ГКМ. Огромные перспективы развития газовой инфраструктуры и газификации в Республике Саха (Якутия) связаны с проектом «Сила Сибири». После запуска магистрального газопровода «Сила Сибири» в среднесрочной перспективе планируется газифицировать четыре района республики, находящиеся в его створе (Ленский, Аланский, Олекминский и Нерюнгринский). Таким образом, развитие нефтегазового комплекса в ближайшие годы должно стать необходимым условием дальнейшего развития экономики республики.

Для улучшения состояния предприятий угольной промышленности Западного энергорайона Республики Саха (Якутия) необходимо решение следующих задач: внедрение новых производственных мощностей по инвестиционным проектам по глубокой переработке и брикетированию бурых углей на Кировском и Кемпендяйском месторождениях; разработать и внедрить инновационные технологии и проекты в угольную отрасль республики; увеличить бюджетное финансирование для предприятий со сложным финансовым состоянием.

Электроэнергетика Западного энергорайона, ее безопасная и надежная эксплуатация в первую очередь связана с устойчивой и сбалансированной КВГЭС1, 2 ПАО «Якутскэнерго» и Светлинской ГЭС АК «АЛРОСА» (ПАО) в целях 
недопущения разрушения нижнего бьефа Светлинской ГЭС при холостых сбросах отработанной воды с гидроагрегатов грозящего экологическими последствиями. Для достижения энергетической безопасности всего Западного энергорайона необходимо:

- завершить строительство 3 и 4 пусковых комплексов ВЛ-220 кВ Мирный Сунтар - Нюрба и внутри улусных распределительных электрических сетей и трансформаторных подстанций;

- разработать «Программу перевода на электроотопление потребителей Западного энергорайона РС (Я) на период до 2020 года», включающую механизмы и эффективность перевода на электроотопление по каждому населенному пункту Западного энергорайона, обоснованные расчетами и взаимоувязанные с местными бюджетами по обеспечению финансовыми ресурсами, а также приводящие к экономии расходной части бюджетов.

Транспортная инфраструктура занимает одно из приоритетных мест среди основных факторов, определяющих эффективное функционирование экономики Западной Якутии. Характерной особенностью транспортной инфраструктуры в течение последних лет стал ее экономический кризис из-за отсутствия достаточных источников финансирования, физического и морального износа материально-технической базы, диспропорций и неравномерностей размещения и развития, отсутствия рыночного механизма функционирования и управления. Являясь важным фактором вывода экономики региона из экономического кризиса, изза ограниченности выделяемых инвестиций, стала фактически сдерживающим фактором развития экономики. Формирование транспортной инфраструктуры Западной Якутии продолжает осуществляться за счет добывающих отраслей, действующих на территории района.

Анализ входящих материальных потоков имеет четко выраженный распределительный характер, при этом внутренняя цепь доставки характеризуется наличием дополнительных перевалочных пунктов, большими расстояниями (до 1,5 тыс. км) и работает как распределительная сеть. Время и затраты на доставку ресурсов по внутренней сети могут превышать затраты по их продвижению по 
внешней сети. Концентрация значительных финансовых ресурсов на обеспечение завоза больших объемов продукции в ограниченный срок вынуждает предприятия искать способы удешевления транспортных издержек. Расчеты, выполненные исследователями показывают, что использование перспективных схем завоза грузов на Мирнинскую и Ленскую площадки дает существенную экономию средств.

Наблюдаемые в последнее десятилетие проблемы снижения уровней воды в верховьях реки Лены из-за маловодности и недостаточного финансирования работ по проведению дноуглубительных работ, вызывают опасения полного переключения грузопотоков на сухопутные виды транспорта.

На территории Западной Якутии в рамках Концепции развития транспортной системы Дальневосточного федерального округа предлагается к формированию и развитию: мультимодальный транспортно-логистический центр регионального уровня в г. Ленск проектной мощностью 120 тыс.т./год.

Комплексное развитие транспортной инфраструктуры Западной Якутии, включающей логистический центр, автомобильные и железнодорожные сети, позволит Республике Саха (Якутия) реализовать политику пространственного развития региона - создание всесезонной опорной сети, активно включится в межрегиональную и международную кооперацию, повысить экономическую безопасность данного региона и России в целом. Реализация стратегии развития транспортной инфраструктуры Западной Якутии с целью решения проблем своевременного и бесперебойного удовлетворения быстрорастущего спроса потребителей услуг с минимизацией затрат вызывает необходимость опережающего и ускоренного её формирования.

Учитывая вышесказанное, транспортная инфраструктура Западной Якутии требует реализации стратегии развития, основанной на интеграционном взаимодействии хозяйствующих в нем субъектов с федеральными и региональными властями. 
Из-за различий в экономической специализации и людности периферийные и полупериферийные относительно г. Якутска поселения Западной Якутии существенно дифференцированы по уровню социально-экономического развития и потенциалу. Выделяются муниципалитеты с относительно устойчивым экономическим положением и депрессивные территории. Деградация сельских поселений сопровождается концентрацией ресурсов и населения в зонах роста.

В 2002-2016 гг. в малых поселениях (с численностью до 200 человек) прослеживается тенденция к снижению средней людности (на 8\%), основной причиной является продолжающаяся миграция сельского населения в города и более крупные поселения, в которых более качественная социальная инфраструктура, доступны рабочие места. В остальных группах этот показатель либо относительно стабилен, либо растет. Существенно сократилось число крупных поселений, прежде всего за счет промышленных поселков, где закрылись нерентабельные в рыночных условиях производства. Свою лепту в эту тенденцию вносит и внедрение новых технологий, повышающих производительность труда на горнодобывающих предприятиях. Все это подтверждает наличие тренда к «сжатию» экономического пространства региона, что соответствует общероссийским и общемировым трендам. Процессы трансформации системы расселения в Западной Якутии в целом неоднозначны, укрупнение поселений усиливает очаговость развития региона.

Анализ транспортной доступности поселений Западной Якутии, анализ показал, что труднодоступны 24 поселения или 21\% от общего числа, 58 поселений являются изолированными (50\%); доступны 33 поселения (29\%).

Оценка специализации на основе типологии Фишера-Кларка показала, что промышленные и аграрные районы различаются по основным параметрам рынка труда и структуре занятости. Для районов промышленной специализации характерен достаточно высокий удельный вес первичной занятости, от 16 до 33\%, в то время как в аграрных районах удельный вес занятых в этой группе не превышает 
4-6\%. Вместе с тем, во всех поселениях отмечается крайне высокий удельный вес занятых в третичном секторе, от 64 до 94\%.

Основной проблемой Западной Якутии является снижение численности населения, что отражается на географическом потенциале поселений и их агломерационном эффекте. За период с 2002-2016 гг. эти показатели снизились на 6,1\%. Рост географического потенциала отмечается только в с. Верхневилюйск; а агломерационного эффекта - в 25 поселениях Верхневилюйского, Вилюйского, Горного, Ленского, Нюрбинского и Сунтарского районов. В дальнейших исследованиях, эти данные следует дополнить расстояниями по наземным путям сообщения, что позволит построить регрессионные уравнения для оценки рыночного потенциала поселений Якутии и размещения различных видов экономической деятельности.

Характеристика демографических процессов, воспроизводства населения, миграционных потоков показал, что в демографическом развитии районов Западной Якутии присутствуют как общие с республикой тренды, так и определенные отличия. Как и в республике отмечается сокращение общей численности населения. Миграционный отток полностью не компенсируется растущим естественным приростом. Миграционное сальдо продолжает сохранять отрицательную величину. Естественный прирост хотя и растет, но в меньшей степени по сравнению с республикой в целом.

Улучшение демографической ситуации происходит, главным образом за счет роста рождаемости населения и снижения смертности. Однако по сравнению с республикой в целом рост рождаемости менее заметный, сокращение смертности так же менее ощутимое.

В Западной Якутии отмечается более высокая доля мужчин и несколько более высокий удельный вес трудоспособного населения, чем в среднем по республике. Отмечается так же и более высокая экономико-демографическая нагрузка. 
В целом необходимо отметить достаточно существенную неоднородность входящих в Западную Якутию муниципальных районов, среди которых, прежде всего, выделяется Мирнинский район.

\section{Сиисок литературы}

1. Аргунов И.А. Социальное развитие якутского народа (историко-социологическое исследование образа жизни) / И.А. Аргунов. - Новосибирск: Наука, 1985. $-320 \mathrm{c}$.

2. Барашкова А.С. Северная семья: демографический и социально-экономический аспекты / А.С. Барашкова. - Новосибирск: Наука, 2009.

3. Будаев А. «Сила Сибири» открылась в Якутске / А. Будаев // Эхо столицы, 29 авг. 2014 [Электронный ресурс]. - Режим доступа: http://www.exo-ykt.ru/articles/20/606/11336/ (дата обращения: 20.06.2016).

4. Винокурова Т.3. Возрастная структура населения Якутии / Т.З. Винокурова, Е.Н. Федорова. - Новосибирск: Наука, 2001.

5. Егорова Т.П. Перспективы развития автомобильного транспорта в Республике Саха (Якутия) до 2025 г. / Т.П. Егорова // Региональная экономика: теория и практика. - 2009. - №14. - С. 44-48.

6. Егорова Т.П. Основные направления формирования транспортной системы Республики Саха (Якутия) / Т.П. Егорова, Е.Л. Ершова, К.И. Алексеева // Региональная экономика: теория и практика. - 2011. - №23. - С. 28-33.

7. Ершова Е.Л. Анализ процесса модернизации водного транспорта Республики Саха (Якутия) / Е.Л. Ершова // Региональная экономика: теория и практика. - 2013. - №25. - С. 17-21.

8. Кин А.А. Магистральный трубопровод «Сила Сибири»: основные положения крупномасштабного проекта / А.А. Кин // Регион: экономика и социология. - 2016. - №2 (90). - С. 154-164.

9. Коломак Е.А. Неравномерное пространственное развитие в России: объяснения новой экономической географии / Е.А. Коломак // Вопросы экономики. - 2013. - №2. - С. 132-150. 
10. Коломак Е.А. Анализ механизмов пространственной концентрации (на примере малого бизнеса в Сибирском федеральном округе) / Е.А. Коломак, И.Е. Трубехина // Вестник Новосибирского государственного университета. Серия: Социально-экономические науки. - 2014. - Т. 14. - Вып. 2. - С. 101-117.

11. Коробко В.И. Экономика городского хозяйства: Учеб. пособие для студ. высш. учеб. заведений / В.И. Коробко. - 2-е изд., стер. - М.: Академия, 2008. $160 \mathrm{c}$.

12. К системе ВСТО присоединены уже шесть нефтяных месторождений Якутии Информационно-аналитический портал SakhaNews: сайт [Электронный pecypc]. - Режим доступа: http://www.sakhanews.ru/157816.html (дата обращения: 20.06.2016).

13. О состоянии и использовании минерально-сырьевых ресурсов Российской Федерации в 2014 году: Государственный доклад / Министерство природных ресурсов и экологии РФ. - 2015. - С. 11-58.

14. Мостахова Т.С. Демографическая безопасность региона / Т.С. Мостахова. - Якутск: Изд-во ЯНЦ СО РАН, 2009.

15. Мостахова Т.С. Миграционная подвижность населения Республики Саха (Якутия) / Т.С. Мостахова // Миграционные процессы в Азиатско-Тихоокеанском регионе: история, современность, практики взаимодействия и регулирования: Сб. тр. междунар. науч.-практ. конф. - Владивосток, 2015. - С. 89-92.

16. Мостахова Т.С. Рождаемость в Республике Саха (Якутия): тенденции и особенности / Т.С. Мостахова // Демографические процессы на постсоветском пространстве: Сб. материалов VI Урал. демограф. форума с междунар. участием. - Екатеринбург, 2015. - С. 307-313.

17. Мостахова Т.С. Народонаселение Республики Саха (Якутия): Монография / Т.С. Мостахова [и др.]. - Якутск, 2003. - Т. 2. - 143 с.

18. Николаев М.В. Методика оценки влияния экономики горнодобывающей компании на бюджет региона ресурсного типа (на примере АК «АЛРОСА» / М.В. Николаев, П.В. Гуляев, Т. . Попова // Горный журнал. - 2015. - №3. - С. 4651. 
19. Разработка стандартов структуры и параметров минимальной сети объектов социальной и инженерной инфраструктуры Республики Саха (Якутия), включая разработку алгоритма принятия инвестиционных решений: Отчет НИР / Инженерно-технический институт Северо-Восточного федерального университета им. М.К. Аммосова. - Якутск, 2014.

20. Отчет отдела региональных экономических и социальных исследований ЯНЦ СО РАН, согласно Плана научно-исследовательской работы (государственного задания) «Фундаментальные научные исследования в соответствии с Программой фундаментальных исследований (ФНИ) государственных академий наук на 2013-2020 годы» по выполнению блока проекта IX.88.1.1. «Определение стратегических направлений и прогнозирование социально-экономического развития северных регионов» с научным направлением исследований «Анализ и прогнозирование социально-экономического развития Республики Саха (Якутия)». -2014.

21. Панасюк М.В. Теоретические основы анализа системы «центр - периферия» региона / М.В. Панасюк, А.В. Руденко // Территориальные общественные системы: проблемы делимитации, развития, управления. - Пермь, 2005. - С. 4752.

22. Пояснительная записка к отчету о финансово-хозяйственной деятельности АО «СК «АЛРОСА-Лена» за 2015 год // Судоходная компания «АлросаЛена»: сайт [Электронный ресурс]. - Режим доступа: www.alrosalena.ru (дата обращения 01.12.2016).

23. Сукнева С.А. Демографический потенциал развития населения северного региона / С.А. Сукнева. - Новосибирск: Наука, 2010. - 167 с.

24. Сукнева С.А. Демографическое развитие региона: оценка, прогноз, политика / С.А. Сукнева, Т. С. Мостахова. - Новосибирск: Изд-во СО РАН, 2002. $192 \mathrm{c}$.

25. Сукнева С.А. О положении народонаселения в Республике Саха (Якутия): территориальные особенности демографических процессов: Доклад / С.А. Сукнева, Т.С. Мостахова. - Якутск: ВИЗИТ КАРД, 2010. 
26. Туманова Д.В. Динамика смертности населения Республики Саха (Якутия) в условиях социально-экономических трансформаций / Д.В. Туманова // Coвременные проблемы межнациональных и межконфессиональных отношений: Материалы Всерос. науч.-практ. конф. - Якутск, 2016. - С. 289-291.

27. Федорова Е.Н. Население Якутии: прошлое и настоящее: Геодемографическое исследование / Е.Н. Федорова. - Новосибирск: Наука, 1998.

28. Федорова Е.Н. Миграции населения Якутии: прошлое и настоящее / Е.Н. Федорова, Г.А. Железнова. - Новосибирск: Наука, 2003.

29. Combes P.-P. The Rise and Fall of Spatial Inequalities in France: A LongRun Perspective / P.-P. Combes, M. Lafourcade, J.-F. Thisse, J.-C. Toutain // Explorations in Economic History. - 2011. - №48. - P. 243-271.

30. «Похудевший» рубль заметно снизил стоимость «Силы Сибири» в долларах [Электронный ресурс] // NewsBox: сайт. [Электронный ресурс]. - Режим доступа: http://teknoblog.ru/2016/07/12/64845/ (дата обращения: 20.06.2016).

31. Pakhomov A.A. Transformation of demographic processes in Yakutia / A.A. Pakhomov, T.S. Mostakhova // Regional Research of Russia. - 2015. - T. 5. №1. - C. 31-36.

Пахомов Александр Алексеевич - д-р экон. наук, заместитель председателя по науке, заведующий отделом региональных экономических и социальных исследований ФГБУН Якутский научный центр Сибирского отделения Российской академии наук, Россия, Якутск.

Pakhomov Aleksandr Alekseevich - doctor of economic sciences, deputy head on the science, head of the Department of Regional Economic and Social Research FSBIS Yakut Scientific Centre of the Siberian Branch of the Russian Academy of Sciences, Russia, Yakutsk. 